\title{
The Number of Harvested LNs Is an Independent Prognostic Factor in Lymph Node Metastasis-negative Patients Who Received Curative Esophagectomy
}

\author{
TORU AOYAMA ${ }^{1 *}$, YOSUKE ATSUMI ${ }^{1 *}$, SHINNOSUKE KAWAHARA ${ }^{1}$, HIROSHI TAMAGAWA $^{1}$, \\ AYAKO TAMAGAWA ${ }^{1}$, YUKIO MAEZAWA ${ }^{1,2}$, KAZUKI KANO ${ }^{1}$, MASAAKI MURAKAWA ${ }^{1}$, \\ KEISUKE KAZAMA $^{1}$, MASAKATSU NUMATA ${ }^{1}$, TAKASHI OSHIMA ${ }^{1,3}$, \\ NORIO YUKAWA ${ }^{1}$, MUNETAKA MASUDA ${ }^{1}$ and YASUSHI RINO ${ }^{1}$ \\ ${ }^{1}$ Department of Surgery, Yokohama City University, Yokohama, Japan; \\ ${ }^{2}$ Department of Surgery, Tokyo Metropolitan Cancer and \\ Infectious Disease Center Komagome Hospital, Tokyo, Japan; \\ ${ }^{3}$ Department of Gastrointestinal Surgery, Kanagawa Cancer Center, Yokohama, Japan
}

\begin{abstract}
Background/Aim: The aim of the present study was to evaluate the optimal number of harvested LNs (LNs) in patients who were LN metastasis-negative after curative esophagectomy for esophageal cancer. Patients and Methods: Sixty-one patients who underwent curative surgery for esophageal cancer between 2005 and 2017 and diagnosed as lymph node metastasis-negative were included in this study. Results: The 5-year overall survival rates were $27.8 \%$ for 0-20 harvested LNs, 35.7\% for 21-30 harvested LNs, $79.4 \%$ for 31-40 harvested LNs, and $85.2 \%$ for $\geq 41$ harvested LNs. Thirty harvested LNs was regarded as the optimal critical point of classification, considering the 5year OS rate. The number of harvested LNs was selected as a significant prognostic factor in both univariate and multivariate analyses. The respective 3-and 5-year OS rates were $50.3 \%$ and $36.7 \%$ for $<30$ harvested LNs and $82.4 \%$ and $82.4 \%$ for $\geq 30$ harvested LNs $(p=0.003)$. Conclusion: Thirty or more harvested LNs was a significant prognostic factor in patients with metastasis-negative LNs after curative esophagectomy for esophageal cancer. Therefore, the number of harvested LNs might be useful for predicting the LN metastasis status in esophageal cancer.
\end{abstract}

This article is freely accessible online.

*These Authors contributed equally to this study.

Correspondence to: Toru Aoyama, Department of Gastrointestinal Surgery, Kanagawa Cancer Center, 2-3-2 Nakao, Asahi-ku, Yokohama 241-8515, Japan. E-mail: t-aoyama@lilac.plala.or.jp

Key Words: Esophageal cancer, lymph node, survival, recurrence.
Esophageal cancer is the seventh-most common cancer in the world and the sixth leading cause of cancer-related mortality (1). Esophagectomy and perioperative adjuvant treatment are essential for curing resectable esophageal cancer (2-4). However, more than half of esophageal cancer patients suffer recurrence, even after curative treatment $(5,6)$. Therefore, it is necessary to identify prognostic factors to improve the chances of survival of patients with esophageal cancer.

The presence of lymph node (LN) metastases in patients with esophageal cancer was one of the most important prognostic factors $(7,8)$. Micrometastasis tumor cells are well known to spread via the lymphatic system, so esophagectomy with lymphadenectomy are established as critical procedures (9-12). Even patients who have been diagnosed as LN metastasis-negative can develop recurrence with a limited prognosis (13-15). The diagnosis of LN metastasis depends on the number of both harvested LNs and metastasis-positive LNs. Therefore, the accuracy of the LN metastasis-negative diagnosis depends on the number of LNs harvested. If the LN metastasis-negative patients do not receive adequate $\mathrm{LN}$ resection or an accurate evaluation of their LNs, the LN metastasis status may be underestimated. However, the TNM staging system does not define the optimal number of LNs to be harvested for accurate nodal staging $(16,17)$. To improve esophageal cancer patients' chances of surviving, it is necessary to develop a more effective way of assessing the lymph node metastasis status.

We hypothesized that the higher number of negative LNs removed during surgery is associated with more accurate staging and an improved survival in LN metastasis-negative patients. To confirm our hypothesis, we investigated the optimal number of harvested LNs in LN metastasis-negative esophageal cancer patients. 
Table I. Comparison of survival rates stratified by patient characteristics.

\begin{tabular}{|c|c|c|c|c|c|}
\hline Characteristics & $\begin{array}{c}\text { No. of patients } \\
(\%)\end{array}$ & $\begin{array}{l}\text { 1-year survival } \\
\text { rate }(\%)\end{array}$ & $\begin{array}{c}\text { 3-year survival } \\
\text { rate }(\%)\end{array}$ & $\begin{array}{c}5 \text {-year survival } \\
\text { rate }(\%)\end{array}$ & $p$-Value \\
\hline Age (years) & & & & & 0.204 \\
\hline$<68$ & $28(45.9)$ & 81.7 & 61.2 & 44.1 & \\
\hline$\geq 68$ & $33(54.1)$ & 84.1 & 73.9 & 65.7 & \\
\hline Gender & & & & & 0.220 \\
\hline Male & $49(80.3)$ & 83.3 & 63.3 & 59.1 & \\
\hline Female & $12(19.7)$ & 90.9 & 90.9 & 72.7 & \\
\hline Site of tumor & & & & & 0.439 \\
\hline Upper & $23(37.7)$ & 82.6 & 64.3 & 64.3 & \\
\hline Middle or Lower & $38(62.3)$ & 83.4 & 70.9 & 61.6 & \\
\hline Number of harvest lymph node & & & & & 0.013 \\
\hline $0-20$ & $10(16.4)$ & 55.6 & 27.8 & 27.8 & \\
\hline $21-30$ & $15(24.6)$ & 85.7 & 57.1 & 35.7 & \\
\hline $31-40$ & $20(32.8)$ & 79.4 & 79.4 & 79.4 & \\
\hline $41-$ & $16(26.2)$ & 93.8 & 85.2 & 85.2 & \\
\hline UICC T status & & & & & 0.253 \\
\hline $\mathrm{T} 1$ & $34(55.7)$ & 94.0 & 72.7 & 72.7 & \\
\hline $\mathrm{T} 2$ to $\mathrm{T} 3$ & $27(44.3)$ & 73.3 & 61.7 & 49.1 & \\
\hline Lymph vascular invasion & & & & & 0.089 \\
\hline Negative & $27(44.3)$ & 88.1 & 83.7 & 83.7 & \\
\hline Positive & $34(55.7)$ & 79.0 & 57.1 & 48.2 & \\
\hline Lymph node dissection & & & & & 0.720 \\
\hline Two-field & $40(65.6)$ & 84.7 & 73.7 & 73.7 & \\
\hline Three-field & $21(34.4)$ & 84.5 & 65.6 & 56.6 & \\
\hline Neoadjuvant therapy & & & & & 0.741 \\
\hline Yes & $28(45.9)$ & 88.9 & 65.3 & 58.1 & \\
\hline No & $33(54.1)$ & 81.8 & 69.6 & 63.2 & \\
\hline
\end{tabular}

UICC: Union for International Cancer Control.

\section{Patients and Methods}

Patients. The medical records of consecutive patients diagnosed with primary esophageal adenocarcinoma or squamous cell carcinoma and who underwent complete resection at Yokohama City University from January 2005 to December 2017 were reviewed.

Surgical procedure. Our standard procedures consisted of open subtotal esophagectomy via right thoracotomy. A greater curvature tube was used for reconstruction. The patients who had tumors in the middle to lower thoracic esophagus received two-field LN dissection, while those with tumors in the upper thoracic esophagus received three-field $\mathrm{LN}$ dissection.

LN harvesting methods and the pathological diagnosis. The LNs were harvested immediately after surgery. First, the surgeons removed the palpable LNs. Second, the surgeons stretched the fat tissues that covered the LNs in order to detect visible LNs. The harvested LNs were then fixed with $10 \%$ buffered formalin for 48 h. After standard histological processing, two-step sections were cut from each block and subjected to Hematoxylin-Eosin (H\&E) staining. Experienced pathologists screened all slides.

Evaluations and statistical analyses. Fisher's exact test or the $\chi^{2}$ test was used to assess the correlation between harvested LNs and each parameter. The Kaplan-Meier method and log-rank test were used to calculate and compare the overall survival (OS) and recurrencefree survival (RFS). Univariate and multivariate survival analyses were performed by a Cox proportional hazards model. $p$ Values of $<0.05$ were considered to indicate statistical significance. The SPSS software program (v11.0 J Win; SPSS, Chicago, IL, USA) was used for all the statistical analyses. This study was approved by the Institutional Review Board of the Yokohama City University.

\section{Results}

Patients. Sixty-one patients were evaluated in the present study. The median age was 68 years old (range $=49-82$ years old). Among them, 49 patients were male, and 12 were female. The median follow-up period was 72.5 months (range=15.0-125.2 months). The median operation time was $572 \mathrm{~min}$ (range=236-911 $\mathrm{min}$ ). The median blood loss was $540 \mathrm{ml}$ (range $=70-3000 \mathrm{ml}$ ). Thirty-six patients received 2field $\mathrm{LN}$ dissection, and 25 received 3-field $\mathrm{LN}$ dissection. The median number of harvested LNs was 31 (range=7-118).

Survival analyses. In Table I, the OS stratified by each clinical factor was compared using the log-rank test. There were significant differences with the number of harvested LNs ( $p=0.013)$ and marginally significant difference with 
Table II. Uni and multivariate Cox proportional hazards analysis of clinicopathological factors for overall survival.

\begin{tabular}{|c|c|c|c|c|c|c|c|}
\hline \multirow[t]{2}{*}{ Factors } & \multirow[t]{2}{*}{ No } & \multicolumn{3}{|c|}{ Univariate analysis } & \multicolumn{3}{|c|}{ Multivariate analysis } \\
\hline & & OR & $95 \%$ CI & $p$-Value & OR & $95 \% \mathrm{CI}$ & $p$-Value \\
\hline Age (years) & & & & 0.233 & & & \\
\hline$<68$ & 28 & 1.000 & & & & & \\
\hline$\geq 68$ & 33 & 1.876 & $0.668-5.272$ & & & & \\
\hline Gender & & & & 0.114 & & & \\
\hline Female & 12 & 1.000 & & & & & \\
\hline Male & 49 & 4.035 & $0.717-22.271$ & & & & \\
\hline Number of harvest lymph node & & & & 0.006 & & & 0.003 \\
\hline$<30$ & 25 & 1.000 & & & 1.000 & & \\
\hline$\geq 30$ & 36 & 3.784 & $1.467-9.763$ & & 3.970 & $1.607-9.806$ & \\
\hline Site of tumor & & & & 0.238 & & & \\
\hline Middle or Lower & 38 & 1.000 & & & & & \\
\hline Upper & 23 & 1.772 & $0.686-4.582$ & & & & \\
\hline UICC T status & & & & 0.146 & & & \\
\hline $\mathrm{T} 1$ & 34 & 1.000 & & & & & \\
\hline $\mathrm{T} 2$ or $\mathrm{T} 3$ & 27 & 2.563 & $0.721-9.108$ & & & & \\
\hline Lymphovascular invasion & & & & 0.161 & & & \\
\hline Negative & 27 & 1.000 & & & & & \\
\hline Positive & 34 & 2.112 & $0.742-6.012$ & & & & \\
\hline Lymph node dissection & & & & 0.161 & & & \\
\hline Two-field & 40 & 1.000 & & & & & \\
\hline Three-field & 21 & 1.158 & $0.396-3.386$ & & & & \\
\hline Neoadjuvant therapy & & & & 0.534 & & & \\
\hline Yes & 28 & 1.000 & & & & & \\
\hline No & 33 & 1.490 & $0.423-5.246$ & & & & \\
\hline
\end{tabular}

UICC: Union for International Cancer Control.

lymphovasuclar invasion $(p=0.089)$. Thirty harvested LNs was regarded as the optimal critical point of classification, considering the 3- and 5-year OS rates. The 3-year OS rates were $27.8 \%$ for $0-20$ harvested $\mathrm{LNs}, 57.1 \%$ for $21-30$ harvested LNs, $79.4 \%$ for 31-40 harvested LNs, and $85.2 \%$ for $\geq 41$ harvested LNs. The 5-year OS rates were $27.8 \%$ for 0-20 harvested LNs, 35.7\% for 21-30 harvested LNs, $79.4 \%$ for $31-40$ harvested $\mathrm{LNs}$, and $85.2 \%$ for $\geq 41$ harvested LNs.

Table II shows the results of univariate and multivariate analyses of the prognostic significance for the OS. The number of harvested LNs was found to be a significant prognostic factor in both the univariate and multivariate analyses. The respective 3- and 5-year OS rates were 50.3\% and $36.7 \%$ for $<30$ harvested LNs and $82.4 \%$ and $82.4 \%$ for $\geq 30$ harvested LNs $(p=0.003)$. Figure 1 shows the OS curves for $<30$ harvested LNs and $\geq 30$ harvested LNs.

Table III shows the results of univariate and multivariate analyses of the prognostic significance for the RFS. The number of harvested LNs, UICC T status, and tumor location were found to be significant prognostic factors in both the univariate and multivariate analyses. The respective 3 - and 5-year RFS rates were $42.5 \%$ and $29.1 \%$ for $<30$ harvested LNs and $67.2 \%$ and $67.2 \%$ for $\geq 30$ harvested LNs ( $p=0.003$ ).
Figure 2 shows the RFS curves for $<30$ harvested LNs and $\geq 30$ harvested LNs.

Table IV compares the sites of first relapse between $<30$ harvested LNs and $\geq 30$ harvested LNs. When comparing the sites of first relapse, the incidence of bone metastasis was significant for $<30$ harvested LNs than for $\geq 30$ harvested LNs. In addition, regarding the local site of recurrence, lung metastasis, and liver metastasis were marginally but significantly higher for $<30$ harvested LNs than for $\geq 30$ harvested LNs.

\section{Discussion}

The aim of the present study was to evaluate the optimal number of harvested LNs in patients who were considered LN metastasis-negative after curative esophagectomy for esophageal cancer. The major finding of the present study was that $\geq 30$ harvested LNs was a significant prognostic factor for patients with LN metastasis-negative status after curative esophagectomy for esophageal cancer. Therefore, the number of harvested LNs might be useful for predicting the LN metastasis status in esophageal cancer.

The present study demonstrated that the number of harvested LNs was a significant risk factor for esophageal 


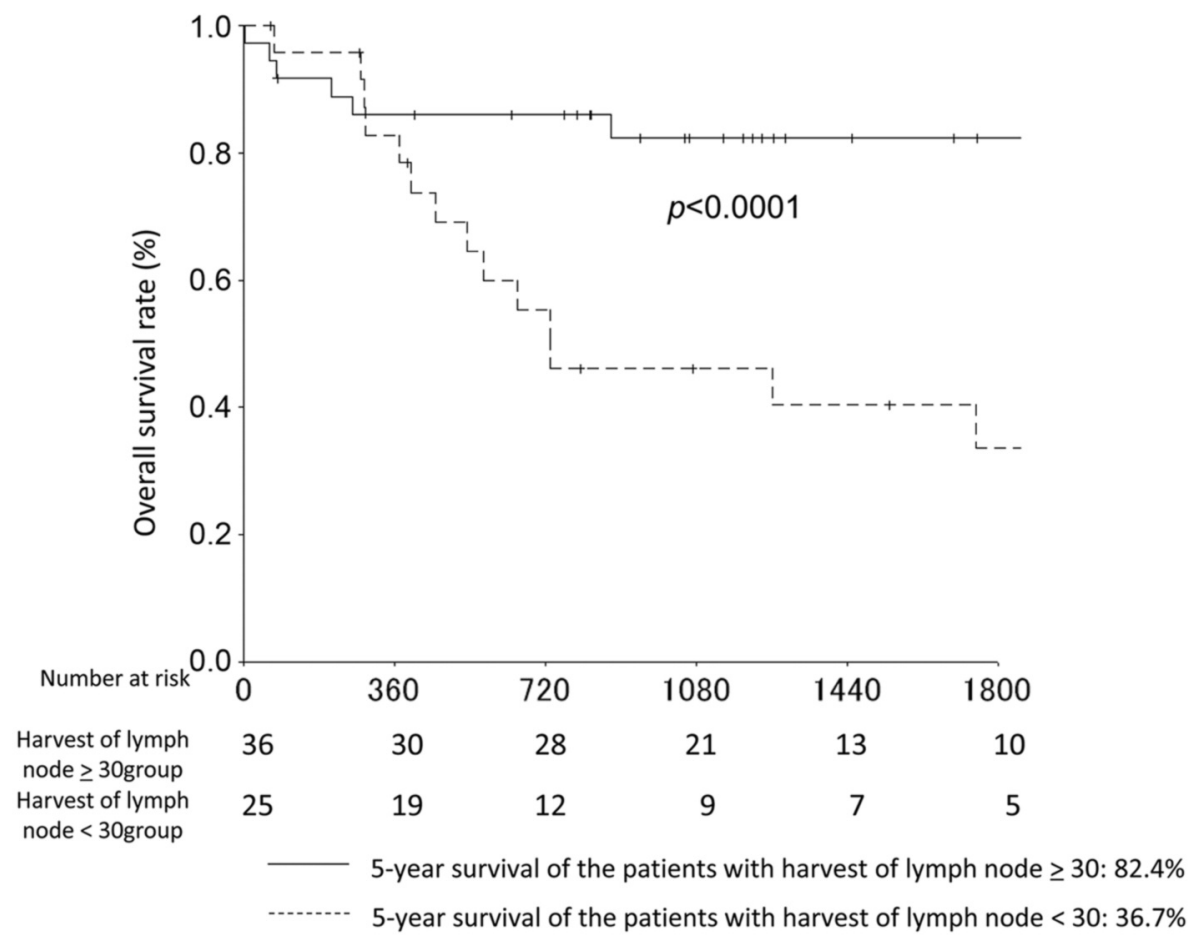

Figure 1. A comparison of the overall survival for $<30$ harvested LNs and $\geq 30$ harvested LNs.

Table III. Uni and multivariate Cox proportional hazards analysis of clinicopathological factors for recurrence free survival.

\begin{tabular}{|c|c|c|c|c|c|c|c|}
\hline \multirow[t]{2}{*}{ Factors } & \multirow[t]{2}{*}{ No } & \multicolumn{3}{|c|}{ Univariate analysis } & \multicolumn{3}{|c|}{ Multivariate analysis } \\
\hline & & OR & $95 \% \mathrm{CI}$ & $p$-Value & OR & $95 \% \mathrm{CI}$ & $p$-Value \\
\hline Age (years) & & & & 0.820 & & & \\
\hline$<68$ & 28 & 1.000 & & & & & \\
\hline$\geq 68$ & 33 & 1.115 & $0.437-2.845$ & & & & \\
\hline Gender & & & & 0.174 & & & \\
\hline Female & 12 & 1.000 & & & & & \\
\hline Male & 49 & 2.503 & $0.666-9.405$ & & & & \\
\hline Number of harvest lymph node & & & & 0.118 & & & 0.026 \\
\hline$<30$ & 25 & 1.000 & & & 1.000 & & \\
\hline$\geq 30$ & 36 & 2.015 & $0.837-4.849$ & & 2.540 & $1.119-5.766$ & \\
\hline Site of tumor & & & & 0.023 & & & 0.046 \\
\hline Middle or Lower & 38 & 1.000 & & & 1.000 & & \\
\hline Upper & 23 & 2.972 & $1.159-7.625$ & & 2.392 & $1.014-5.645$ & \\
\hline UICC T status & & & & 0.017 & & & 0.010 \\
\hline $\mathrm{T} 1$ & 34 & 1.000 & & & 1.000 & & \\
\hline $\mathrm{T} 2$ or $\mathrm{T} 3$ & 27 & 3.977 & $1.287-12.292$ & & 3.107 & $1.317-7.329$ & \\
\hline Lymphovascular invasion & & & & 0.142 & & & \\
\hline Negative & 27 & 1.000 & & & & & \\
\hline Positive & 34 & 2.081 & $0.783-5.531$ & & & & \\
\hline Lymph node dissection & & & & 0.384 & & & \\
\hline Two-field & 40 & 1.000 & & & & & \\
\hline Three-field & 21 & 1.624 & $0.546-4.833$ & & & & \\
\hline Neoadjuvant therapy & & & & 0.392 & & & \\
\hline Yes & 28 & 1.000 & & & & & \\
\hline No & 33 & 1.618 & $0.537-4.875$ & & & & \\
\hline
\end{tabular}

UICC: Union for International Cancer Control. 


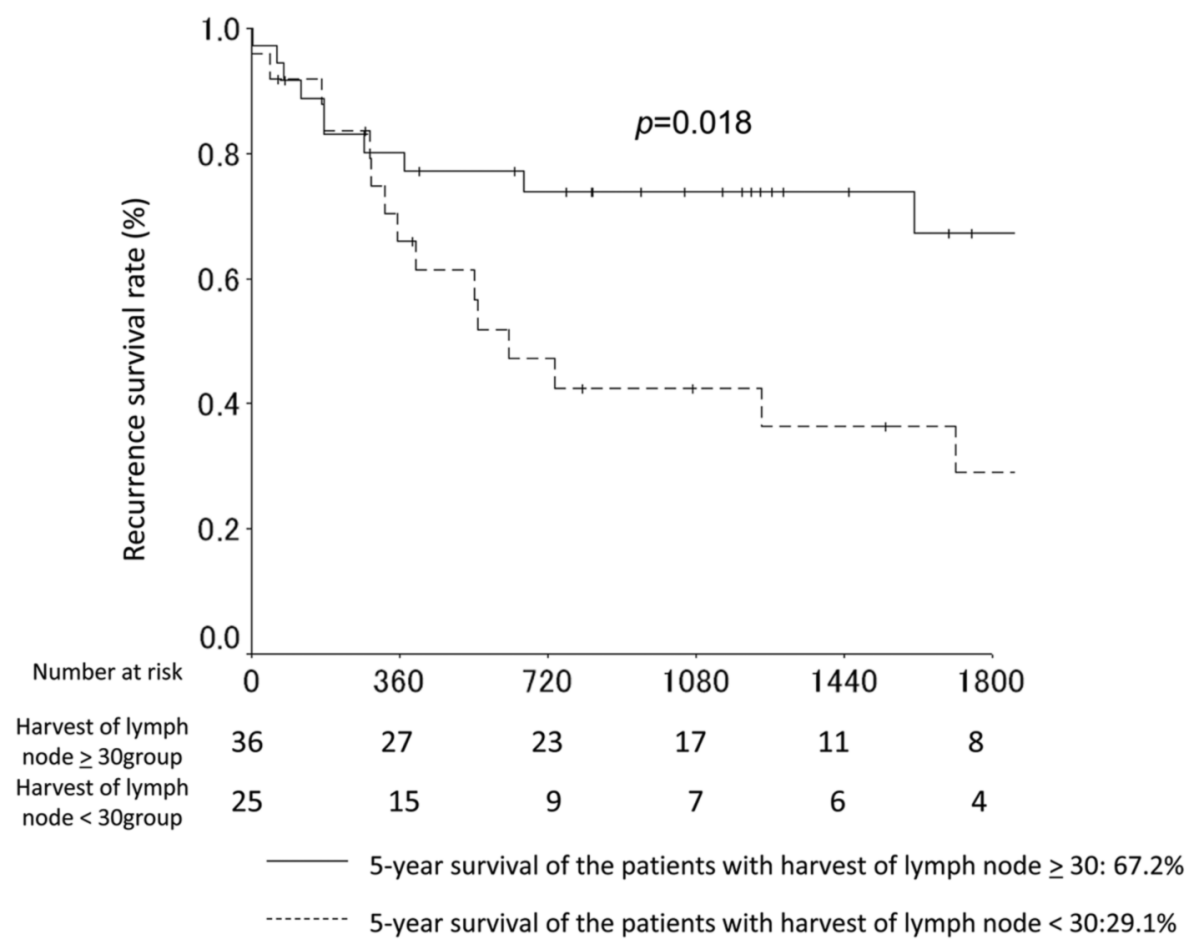

Figure 2. A comparison of the recurrence-free survival for $<30$ harvested LNs and $\geq 30$ harvested LNs.

Table IV. Patterns of recurrence between the patients with $<30$ harvested lymph nodes and those with $\geq 30$ harvested lymph nodes.

\begin{tabular}{|c|c|c|c|c|c|c|c|}
\hline \multirow[b]{2}{*}{ Recurrence site } & \multicolumn{2}{|c|}{ All cases } & \multicolumn{2}{|c|}{$<30(n=25)$} & \multicolumn{2}{|c|}{$\geq 30(n=36)$} & \multirow[b]{2}{*}{$p$-Value } \\
\hline & Number & $\%$ & Number & $\%$ & Number & $\%$ & \\
\hline \multicolumn{8}{|l|}{ Lymph node } \\
\hline Regional & 8 & 13.1 & 5 & 20.0 & 3 & 8.3 & 0.184 \\
\hline Distant & 2 & 3.3 & 1 & 4.0 & 1 & 2.8 & 0.792 \\
\hline Local site & 5 & 8.2 & 4 & 16.0 & 1 & 2.8 & 0.064 \\
\hline \multicolumn{8}{|l|}{ Distant site } \\
\hline Lung & 7 & 11.5 & 5 & 20.0 & 2 & 5.6 & 0.082 \\
\hline Liver & 2 & 3.3 & 2 & 8.0 & 0 & 0.0 & 0.084 \\
\hline Bone & 3 & 4.9 & 3 & 12.0 & 0 & 0.0 & 0.033 \\
\hline Others & 4 & 6.6 & 2 & 8.0 & 2 & 5.6 & 0.704 \\
\hline
\end{tabular}

cancer patients after esophagectomy. Limited studies have shown similar results. Greenstein et al. have evaluated the prognostic impact of the total number of harvested LNs in 972 LN metastasis-negative esophageal cancer patients who received curative esophagectomy (18). They divided the 972 patients into 3 groups according to the number of harvested LNs $(0-10,11-17$, and $\geq 18)$ and found that the total number of harvested LNs was significantly linked to the diseasespecific survival rates. The 5-year survival rate was $55 \%$ for 0-10 harvested LNs, 66\% for 11-17 harvested LNs, and 75\% for $\geq 18$ harvested LNs. They also found that the total number of harvested LNs was an independent prognostic factor for esophageal cancer patients' survival after curative esophagectomy in a multivariate analysis (hazard ratio $=3.16$, $95 \%$ confidence interval $=1.34-7.43, p=0.02$ ). They suggested that patients undergoing surgical resection for esophageal cancer should have at least $18 \mathrm{LNs}$ removed.

In addition, Yu et al. evaluated the prognostic influence of the total number of harvested LNs in 576 esophageal cancer patients who received curative esophagectomy (19). They divided the 
576 patients into 4 groups according to the number of harvested LNs $(0-9,10-14,15-19$, and $\geq 20)$ and found that the total number of harvested LNs was significantly linked to the survival rates. The 3-year survival rate was $21.7 \%$ for $0-9$ harvested LNs, $40.0 \%$ for $10-14$ harvested LNs, $61.2 \%$ for NLNs of $15-19$ harvested LNs, and $77.5 \%$ for $\geq 20$ harvested LNs. They also found that the total number of harvested LNs was an independent prognostic factor for esophageal cancer patients' survival after curative esophagectomy in a multivariate analysis. Taken together, our results and those of other investigators suggest that the number of harvested LNs may influence survival of esophageal cancer patients after curative surgery.

In the present study, we set the cut-off value of harvested LNs at 30, based on the 3- and 5-year OS rates. The cut-off value for harvested LNs differed somewhat between the present and previous studies. An important limitation to consider concerning the available data on harvested LNs, including those from the current study, is the lack of a consensus regarding the most appropriate cut-off point for the evaluation of harvested LNs. Mo et al. set the cut-off value at 21 in their study of 768 esophageal cancer patients, Greenstein et al. set the cut-off value at 18 in their study of 972 esophageal cancer patients, and Xia et al. set the cut-off value at 14 and 15 in their study of 7356 esophageal cancer patients $(18,20,23)$. Of course, there are some differences between the present and previous studies that should be mentioned. First, the sample size was differed among studies. Second, the perioperative adjuvant treatment approach was also differed among studies. Previous reports analyzed only patients who were treated with surgery alone, while the present study analyzed only those who had been treated with surgery as well as perioperative adjuvant treatment. The outcomes of patients with esophageal cancer have gradually improved due to effective adjuvant treatment. Theoretically, effective adjuvant treatment could improve the patient survival by inhibiting micrometastases. Indeed, a previous study has shown that perioperative adjuvant treatment was associated with a reduced LN ratio in other gastrointestinal cancers $(21,22)$. Third, the median number of harvested LNs was differed among the studies. In the present study, the median number of harvested LNs was 31, and the cut-off value of the LNs was 30. In contrast, Mo et al. have reported that the mean number of harvested LNs was 23, and the cut-off value of harvested LNs was set at 21 (23). Furthermore, Xia et al. have reported that the median number of harvested LNs was 12, and the cut-off value of harvested LNs was set at 14 and 15 (20). These differences might have affected the cut-off values of the harvested LNs.

Special attention is required when interpreting the present findings, as this study is associated with several potential limitations. First, our study was a retrospective analysis performed in a single institution. We cannot deny the possibility that our findings were observed by chance. Second, there was a selection bias in the patients in this series. Surgeons often avoid performing esophagectomy in some patients because the procedure is associated with high rates of morbidity and mortality $(40 \%-60 \%$ and $1-5 \%$, respectively). Third, there was a time bias in the present study, as the surgical procedure, perioperative care, and adjuvant treatment changed throughout the study period. Given these limitations, the results must be confirmed in another cohort or in a prospective, multicenter study.

In conclusion, the OS and RFS of LN metastasis-negative esophageal cancer patients who underwent curative surgery differed significantly based on the number of harvested LNs. It is necessary to develop an effective means of using the LN metastasis status in these patients.

\section{Conflicts of Interest}

The Authors declare no conflicts of interest in association with the present study.

\section{Authors' Contributions}

Toru Aoyama and Yosuke Atsumi made substantial contributions to conception and design. Norio Yukawa, Toru Aoyama, Hiroshi Tamagawa, Ayako Tamagawa, Yosuke Atsumi, Shinnosuke Kawahara, Yukio Maezawa, Kazuki Kano, Masaaki Murakawa, Keisuke Kazama, Masakatsu Numata, Takashi Oshima, Munetaka Masuda,and Yasushi Rino made substantial contributions to acquisition of data, or analysis and interpretation of data. Norio Yukawa, Toru Aoyama, Hiroshi Tamagawa, Ayako Tamagawa, Yosuke Atsumi, and Shinnosuke Kawahara have been involved in drafting the manuscript or revising it critically for important intellectual content. Norio Yukawa, Toru Aoyama, Hiroshi Tamagawa, Ayako Tamagawa, Yosuke Atsumi, and Shinnosuke Kawahara have given final approval of the version to be published. Each author should have participated sufficiently in the work to take public responsibility for appropriate portions of the content; and agreed to be accountable for all aspects of the work in ensuring that questions related to the accuracy or integrity of any part of the work are appropriately investigated and resolved. All Authors read and approved the final manuscript.

\section{Acknowledgements}

This work was supported, in part, by the nongovernmental organization Yokohama Surgical Research Group, Dr. Masumi Kamachi (Tokyo Shinagawa Hospital), Dr. Ryuji Tominaga (Fukuoka Wajiro Hospital), Dr. Nobuko Yoshiki (Yoshiki Dermatology Clinic Ginza). The authors express their sincere gratitude to Ms. Akiko Yoshida, Ms. Yuka Maruyama, Ms. Minako Igarashi and Ms. Mariko Yamauchi for their excellent data management in this study.

\section{References}

1 Bray F, Ferlay J, Soerjomataram I, Siegel RL, Torre LA and Jemal A: Global cancer statistics 2018: GLOBOCAN estimates of incidence and mortality worldwide for 36 cancers in 185 countries. CA Cancer J Clin 68: 394-424, 2018. PMID: 30207593. DOI: $10.3322 /$ caac. 21492 
2 NCCN: NCCN Clinical Practice Guidelines in Oncology. Available at: https://www.nccn.org/professionals/physician_gls/ (Last accessed 18/04/2020)

3 Muro K, Lordick F, Tsushima T, Pentheroudakis G, Baba E, Lu Z, Cho BC, Nor IM, Ng M, Chen LT, Kato K, Li J, Ryu MH, Zamaniah WIW, Yong WP, Yeh KH, Nakajima TE, Shitara K, Kawakami H, Narita Y, Yoshino T, Van Cutsem E, Martinelli E, Smyth EC, Arnold D, Minami H, Tabernero J and Douillard JY: Pan-Asian adapted ESMO Clinical Practice Guidelines for the management of patients with metastatic oesophageal cancer: a JSMO-ESMO initiative endorsed by CSCO, KSMO, MOS, SSO and TOS. Ann Oncol 30: 34-43, 2019. PMID: 30475943. DOI: 10.1093/annonc/mdy498

4 Lordick F, Mariette C, Haustermans K, Obermannová R and Arnold D; ESMO guidelines Committee. Oesophageal cancer: ESMO Clinical Practice Guidelines for diagnosis, treatment and follow-up. Ann Oncol 27: v50-v57, 2016. PMID: 27664261.

5 Kato $\mathrm{H}$ and Nakajima M: Treatments for esophageal cancer: a review. Gen Thorac Cardiovasc Surg 61: 330-335, 2013. PMID: 23568356. DOI: $10.1007 / \mathrm{s} 11748-013-0246-0$

6 Yuequan J, Shifeng C and Bing Z: Prognostic factors and family history for survival of esophageal squamous cell carcinoma patients after surgery. Ann Thorac Surg 90: 908-913, 2010. PMID: 20732516. DOI: 10.1016/j.athoracsur.2010.05.060

7 Hosch SB, Stoecklein NH, Pichlmeier U, Rehders A, Scheunemann P, Niendorf A, Knoefel WT and Izbicki JR: Esophageal cancer: the mode of lymphatic tumor cell spread and its prognostic significance. J Clin Oncol 19: 1970-1975, 2001. PMID: 11283129.

8 Buskens CJ, Ten Kate FJ, Obertop H, Izbicki JR and van Lanschot JJ: Analysis of micrometastatic disease in histologically negative lymph nodes of patients with adenocarcinoma of the distal esophagus or gastric cardia. Dis Esophagus 21: 488-495, 2008. PMID: 18840133. DOI: 10.1111/ j.1442-2050.2007.00805.x

9 Li B, Hu H, Zhang Y, Zhang J, Miao L, Ma L, Luo X, Zhang Y, Ye T, Li H, Li Y, Shen L, Zhao K, Fan M, Zhu Z, Wang J, Xu J, Deng Y, Lu Q, Li H, Zhang Y, Pan Y, Liu S, Hu H, Shao L, Sun $\mathrm{Y}$, Xiang $\mathrm{J}$ and Chen $\mathrm{H}$ : Three-field versus two-field lymphadenectomy in transthoracic oesophagectomy for oesophageal squamous cell carcinoma: short-term outcomes of a randomized clinical trial. Br J Surg, 2020. PMID: 32108326. DOI: $10.1002 /$ bjs.11497

10 Matsuda S, Takeuchi H, Kawakubo H and Kitagawa Y: Threefield lymph node dissection in esophageal cancer surgery. J Thorac Dis 9: S731-S740, 2017. PMID: 28815069. DOI: $10.21037 /$ jtd.2017.03.171

11 Guo JC, Lin CC, Huang TC, Huang PM, Kuo HY, Chang CH, Wang CC, Cheng JC, Yeh KH, Hsu CH and Lee JM: Number of resected lymph nodes and survival of patients with locally advanced esophageal squamous cell carcinoma receiving preoperative chemoradiotherapy. Anticancer Res 38: 1569-1577, 2018. PMID: 29491087.

12 Udagawa H, Ueno M, Shinohara H, Haruta S, Kaida S, Nakagawa $\mathrm{M}$ and Tsurumaru $\mathrm{M}$ : The importance of grouping of lymph node stations and rationale of three-field lymphoadenectomy for thoracic esophageal cancer. J Surg Oncol 106: 742-747, 2012. PMID: 22504922. DOI: 10.1002/jso.23122
13 Yang Y, Zhou X, Tang L, Xu X, Du X and Qiu G: Role of perioperative chemotherapy in lymph node-negative esophageal cancer after resection: A population-based study with propensity score-matched analysis. Am J Clin Oncol 42: 924-931, 2019. PMID: 31651453. DOI: 10.1097/COC.0000000000000624

14 Zhang J, Heng X, Luo Y, Li L, Zhang H, Che F, Li B. Negative lymph node at station 108 is a strong predictor of overall survival in esophageal cancer. Oncol Lett 16: 6705-6712, 2018. PMID: 30405812. DOI: 10.3892/ol.2018.9456

15 Zhou L, Zhao Y, Zheng Y, Wang M, Tian T, Lin S, Hao Q, Xu $\mathrm{P}$, Deng $\mathrm{Y}, \mathrm{Li} \mathrm{N}, \mathrm{Wu} \mathrm{Y}$, Yang $\mathrm{T}$, Kang $\mathrm{H}$ and Dai $\mathrm{Z}$ : The prognostic value of the number of negative lymph nodes combined with positive lymph nodes in esophageal cancer patients: a propensity-matched analysis. Ann Surg Oncol, 2020. PMID: 31898102. DOI: 10.1245/s10434-019-08083-3

16 Sobin LH, Gospodarowicz MK and Wittekind Ch: TNM classification of malignant tumours. $7^{\text {th }}$ edition. Chichester, West Sussex, UK; Hoboken, NJ: Wiley-Blackwell, 2010.

17 Brierley J, Gospodarowicz MK and Wittekind Ch: TNM classification of malignant tumours. 8th edition. Chichester, West Sussex, UK; Hoboken, NJ: John Wiley \& Sons, Inc., 2017.

18 Greenstein AJ, Litle VR, Swanson SJ, Divino CM, Packer S and Wisnivesky JP: Effect of the number of lymph nodes sampled on postoperative survival of lymph node-negative esophageal cancer. Cancer 112: 1239-1246, 2008. PMID: 18224663. DOI: $10.1002 /$ cncr.23309

19 Yu L, Zhang XT, Guan SH, Cheng YF and Li LX: The number of negative lymph nodes is positively associated with survival in esophageal squamous cell carcinoma patients in China. Open Med (Wars) 15: 152-159, 2020. PMID: 32190739. DOI: 10.1515/med-2020-0023

20 Xia W, Liu S, Mao Q, Chen B, Ma W, Dong G, Xu L and Jiang F: Effect of lymph node examined count on accurate staging and survival of resected esophageal cancer. Thorac Cancer 10: 11491157, 2019. PMID: 30957414. DOI: 10.1111/1759-7714.13056

21 Ooki A, Akagi K, Yatsuoka T, Asayama M, Hara H, Nishimura Y, Katoh H, Yamashita K, Watanabe M and Yamaguchi K: Lymph node ratio as a risk factor for recurrence after adjuvant chemotherapy in stage III colorectal cancer. J Gastrointest Surg 21: 867-878, 2017. PMID: 28251467. DOI: 10.1007/s11605017-3382-5

22 Ryan ÉJ, O'Sullivan DP, Kelly ME, Syed AZ, Neary PC, O'Connell PR, Kavanagh DO, Winter DC and O'Riordan JM: Meta-analysis of the effect of extending the interval after longcourse chemoradiotherapy before surgery in locally advanced rectal cancer. Br J Surg 106: 1298-1310, 2019. PMID: 31216064. DOI: 10.1002/bjs.11220

23 Mo J, Chen D, Li C and Chen M: The significance of negative lymph nodes in esophageal cancer after curative resection: a retrospective cohort study. Cancer Manag Res 12: 1269-1279, 2020. PMID: 32110101. DOI: 10.2147/CMAR.S232856

Received April 12, 2020

Revised April 17, 2020

Accepted April 18, 2020 